\title{
التحديات التي تواجه مديري المدارس بسلطنة عمان في تحسين مستوى أداء الطلبة في الاختبارات الدولية (TIMSS) وآليات التغلب عليها
}

\author{
منى بنت سعيد بن صالح التوبية'، عمرهاشم إسماعيل حمدّ'، محمد عبد الحميد لاشينَ \\ ا وزارة التربية والتعليم- سلطنة عمان

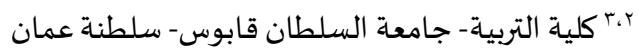

${ }^{1}$ muna.altobi@moe.om, ${ }^{2}$ omerhi@squ.edu.om, ${ }^{3}$ lashin@squ.edu.om

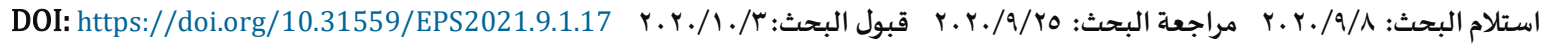

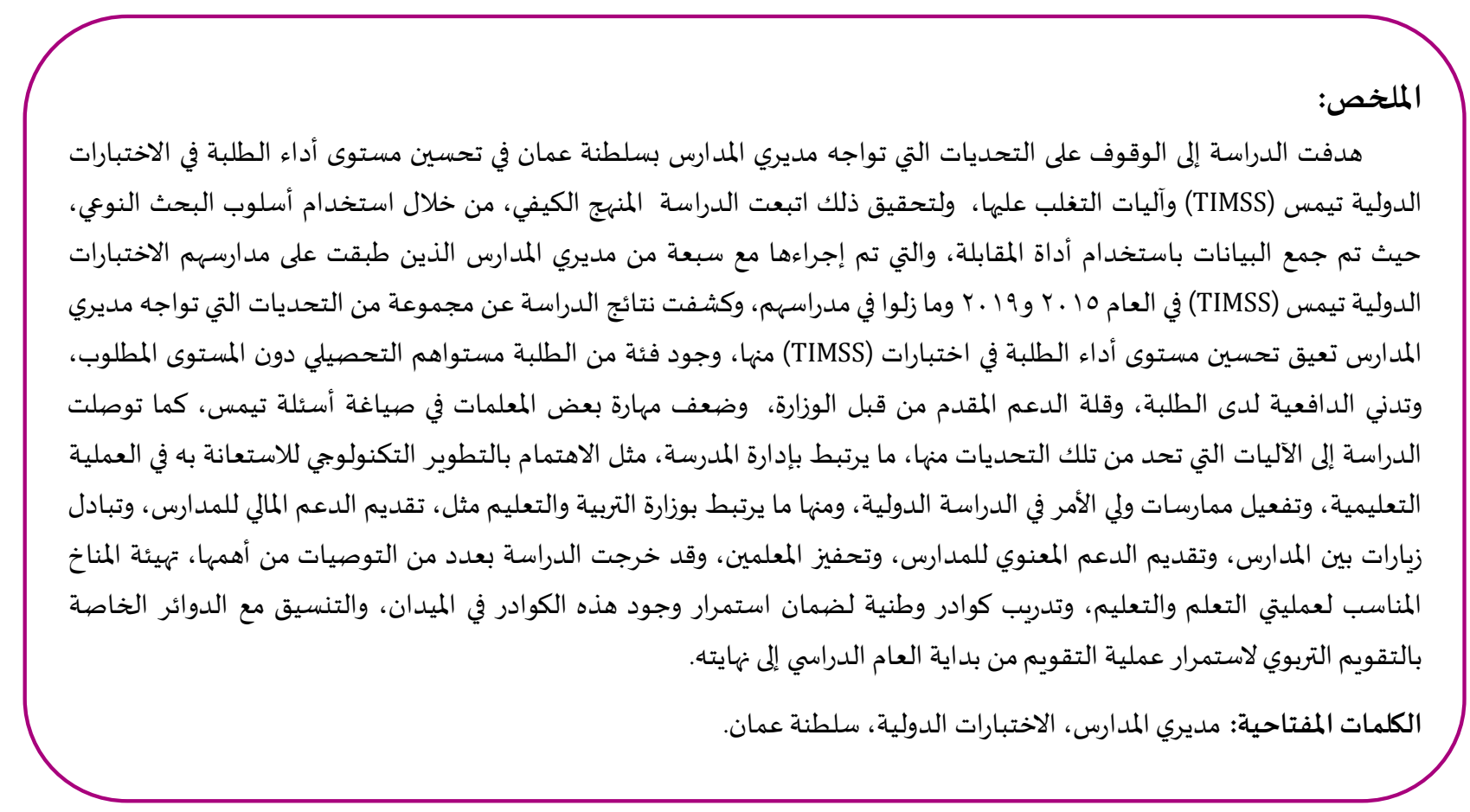

المقدمة:

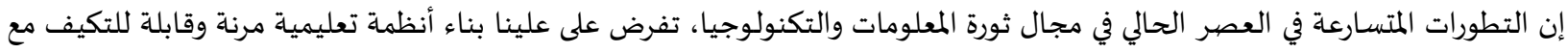

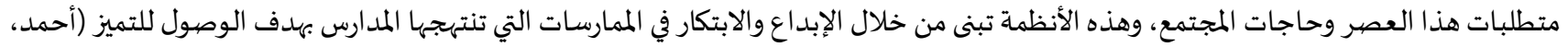

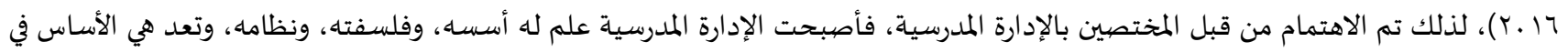

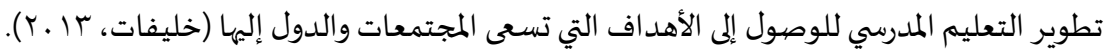

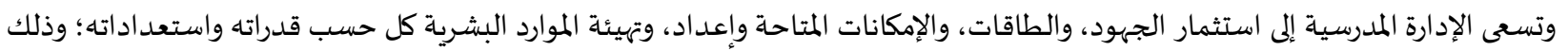

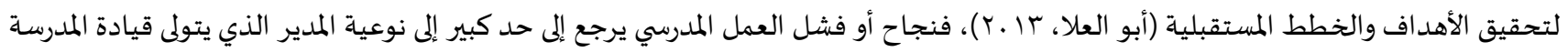

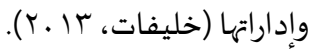

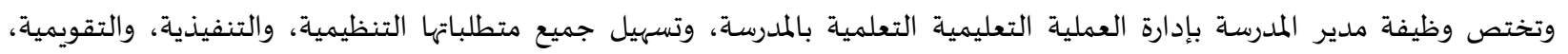

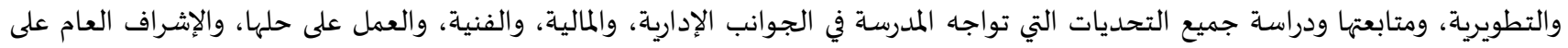

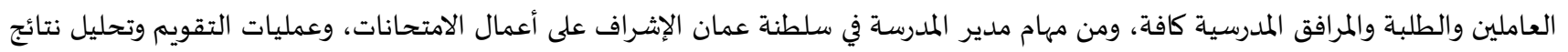


الطلبة، ومساعدة الطلبة على تطوير تحصيلهم الدراسي من خلال الإشراف على إعداد خطط علاجية وإثرائية بالتعاون مع المعلمين الأوائل، كذلك يعمل على التخطيط والتنفيذ للمشاريع التي من شأهها أن ترفع مستوى التحصيل الدراسي للطلبة (اللجنة الرئيسية للسياسـات التربوية وتطوير

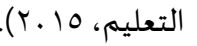

وقد جاءت مشاركة السلطنة في الدراسة الدولية تيمس (TIMSS)، الاتجاهات الدولية في دراسة الرياضيات والعلوم، امتدادًا لنهج التطوير والتحديث الذي تبنته الوزارة، وللاستفادة أيضاً من تجارب الدول الأخرى، وللتعرف على موقع المناهج العمانية على خارطة الأداء في الحقل التربوي

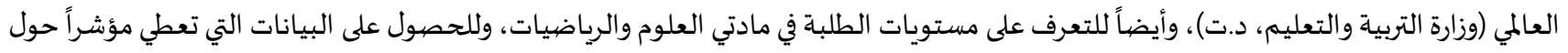

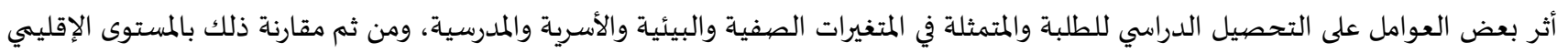

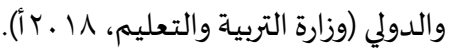

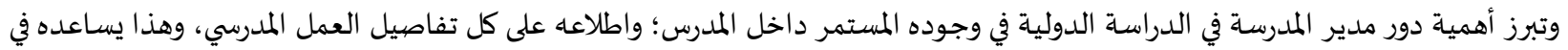
تكوين علاقات إيجابية مع الطلبة، والمعلمين، والعاملين بالمدرسة، أيضاً يستطيع متابعة ومعرفة التطورات التي تحدث داخل المدرساة، ومعرفة المؤثرات

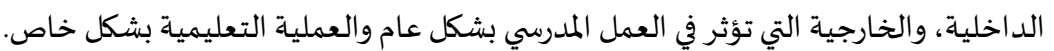

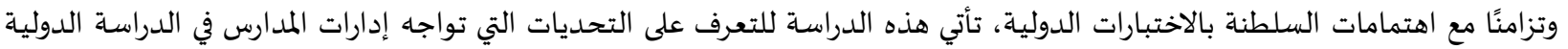
تيمس (TIMSS) بسلطنة عمان.

\section{مشكلة الدراسـة وأسئلتها:}

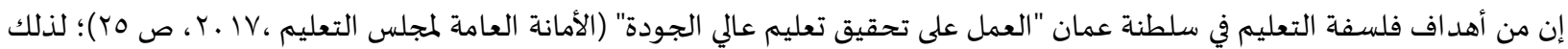
تعمل وزارة التربية والتعليم على تجويد العمل المدرسي من خلال معالجة الأداء الحالي للنظام التعليمي داخل المدارس وذلك وفقا لعدة معايير ومؤشرات

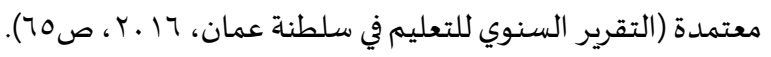
وتبذل وزارة التربية والتعليم العديد من الجهود لتحسين المستويات التحصيلية للطلبة، إلا أن هناك تدني ملحوظ في المستويات لبعض المدارس،

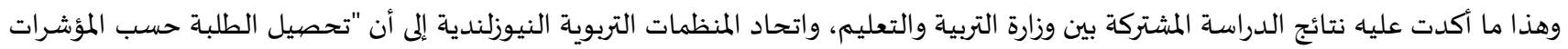

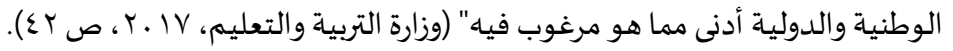
كما أشار التقرير الوطني للدراسة الدولية في الرياضيات والعلوم (TIMSS 2015) لمادة الرياضيات للصفيهين الرابع والثامن، والتقرير الوطني للدراسة الدولية في الرياضيات والعلوم (TIMSS 2015) لمادة العلوم للصفين الرابع والثامن، إلى أن السلطنة احتلت المرتبة (rع) في معدل التحصيل

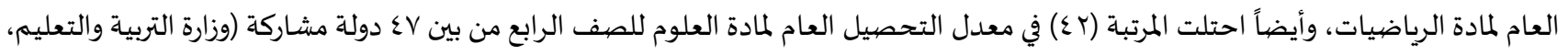

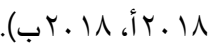

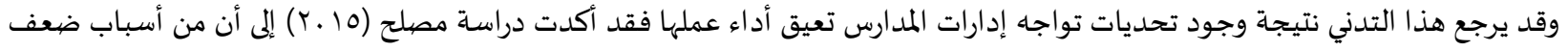

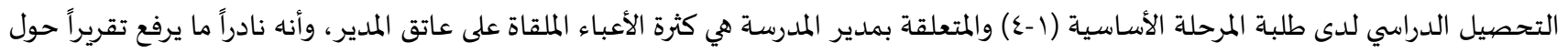
مستوى التحصيل في المدرسـة. وفي ضوء ما سبق تأتي مشكلة الدراسـة للتعرف على التحديات التي تواجه إدارات المدارس في الدراسة الدولية تيمس (TIMSS) بسلطنة عمان من خلال الإجابة عن أسئلة الدراسـة التي تتمثل في في مئي ا. ما التحديات التي تواجه مديري المدارس لتحسين مستوى الطلبة في الدراسة الدولية تيمس (TIMSS)؟ r. ما الآليات المقترحة للتغلب على التحديات التي تواجه مديري المدارس لتحسين مستوى الطلبة في الدراسـة الدولية تيمس (TIMSS)؟

أهداف الدراسة:

تسعى الدراسة الحالية لتحقيق الأهداف التالية: ا. التعرف على التحديات التي واجهت مديري المدارس، التي من شأهها أن تؤثر على المستوى التحصيلي للطلبة في الدراسة الدولية تيمس (TIMSS).

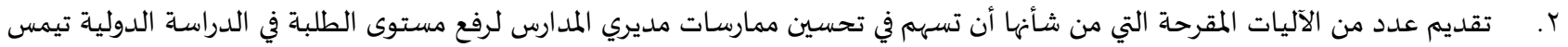

(TIMSS)

أهمية الدراسـة:

تأتي أهمية الدراسـة الحالية لارتباطها بالاختبارات الدولية، وهي اختبارات تهدف إلى تشخيص واقع العملية التعليمية وتطويرها، وتحرص وزارة التربية والتعليم على الاستفادة من هذه الاختبارات؛ لاتخاذ الخطوات اللازمة لتجويد العملية التعليمية التعلمية، ومن المؤمل أن تسهم نتائج الدراسة 
الحالية في تحديد التحديات التي تواجه مديري المدارس، وإيجاد عدد من الآليات المقرحة للتغلب على هذه التحديات لتحسين مستوى الطلبة في

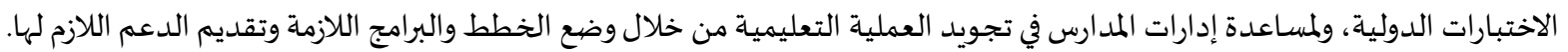

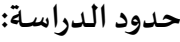

الحدود البشرية: تمثلت عينة الدراسـة في مديري المدارس الذين طبقت على مدارسهم الدراسة الدولية تيمس (TIMSS) في العامين 10 ــو 19 ـأب م.

الحدود الموضوعية: اقتصرت الدراسة على موضوع الدراسة الدولية تيمس (TIMSS). الحدود المكانية: تمثلت الحدود المكانية للدراسة في المدارس التي طبقت فيها الدراسة الدولية تيمس (TIMSS) من ثلاث محافظات هي: جنوب البهاطية البهاطنة، وشمال الباطنة، والبريمي.

مصطلحات الدراسـة:

الاختبارات الدولية (International Tests)

تعد الاختبارات الدولية أداة مهمة لتقويم الأنظمة التعليمية، فهي تعمل على مقارنة التحصيل الدراسي، والجوانب الأخرى للتعليم بين الدول

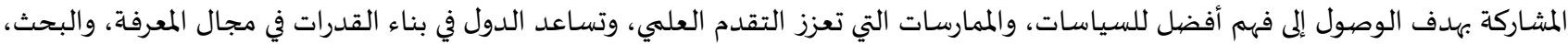

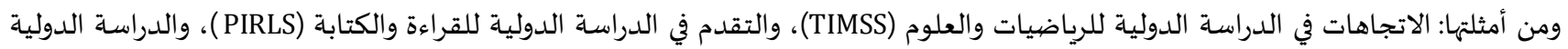
للتربية المدنية والمواطنة (ICCS) والمناتيات والدراسة الدولية للمعرفة في مجال الحاسوب والمعلومات (International Association for the (ICILS)

.Evaluation of Educational Achievement, 2020)

الاتجاهات في الدراسة الدولية للرياضيات والعلوم:Trends in International Mathematics and Science Study (TIMSS) الدراسة الدولية في الرياضيات والعلوم تيمس (TIMSS) هي: دراسـة تُجرى على المستوى الدولي، وتُعنى بدراسة معارف ومهارات وقدرات الطلبة في

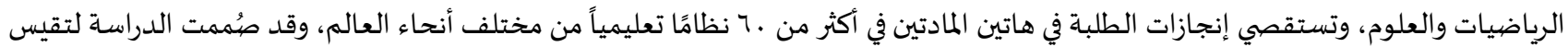
الفروق بين النظم التعليمية الوطنية وتفسير هذه الفروق؛ وذلك للمساعدة في تطوير وتحسين تعليم وتعلم الرياضيات والعلوم في جميع أنحاء العالم

.(Mullis\& Martin, 2017, p.3)

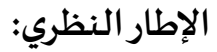

يتناول الإطار النظري مفهوم الدراسة الدولية وأهدافها وادواتها، كما يتناول المشكلات التي تواجه إدارات المدارس في سعيها لتحسين أداء الطلبة في الاختبارات الدولية، وجهود السلطنة في تطبيق هذه الاختبارات، وقد تم عرض ذلك في ثلاثة محاور على النحو التالي:

المحور الأول: الاختبارات الدولية (International Tests)

ا ـ مفهوم الدراسة الدولية في الرياضيات والعلوم (TIMSS)

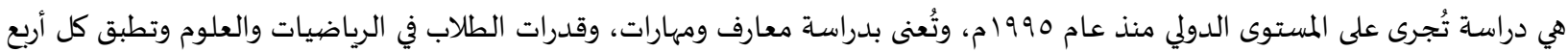

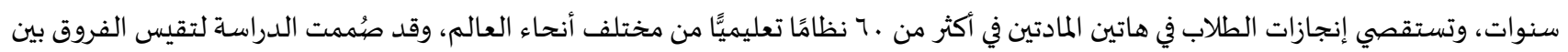

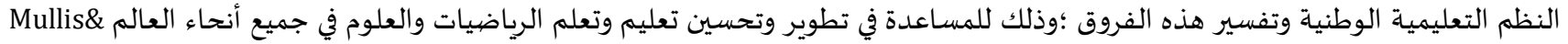

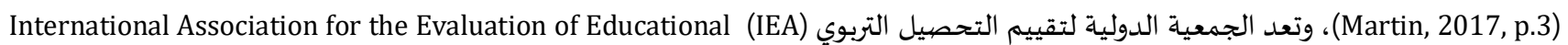
Achievement هي المسؤولة عن قياس تحصيل الطلبة في تيمس (TIMSS). وهي منظمة دولية تعاونية مستقلة وغير ربحية، تضم مؤسسات بحثية

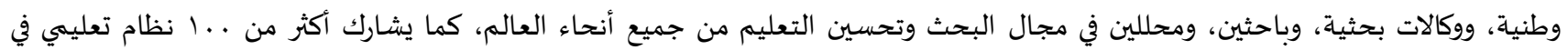

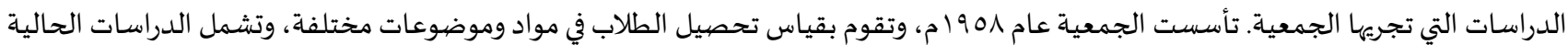

للجمعياة ما يلي: TIMSS (الاتجاهات في الدراسة الدولية للرياضيات والعلوم). PIRLS (التقدم في الدراسـة الدولية للقراءة والكتابة). ICCS ICILS تُجري الجمعية دراسات مقارنة حول التحصيل الدراسي، والجوانب الأخرى للتعليم تهدف إلى فهم أفضل للسياسات، والممارسات التي تعزز التقدم العلمي، وتساعد الدول في بناء القدرات في مجال المعرفة، والبحث، كذلك تسهم الجمعية في بناء عالم أكثر تعليمًا، وتسعى لفهم الروابط بين

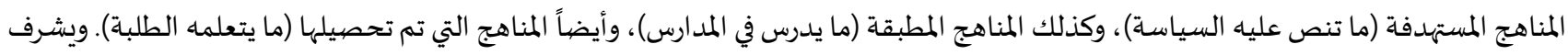


مكتب الجمعية في أمستردام على العمليات اليومية للجمعية ويضم فرق من الزملاء الدوليين، أما مكتب الجمعية في هامبورغ يشمل أنشطة تنسيق

الدراسات الدولية وغير الدولية التي تجريها الجمعية (International Association for the Evaluation of Educational Achievement, 2020).

r T. أهداف الدراسة الدولية تيمس (TIMSS)

تسعى الدراسة الدولية إلى عمل مقارنات بين تحصيل الطلبة في مادتي العلوم والرياضيات في أنظمة تعليمية مختلفة، وبيئات مختلفة اقتصادياً،

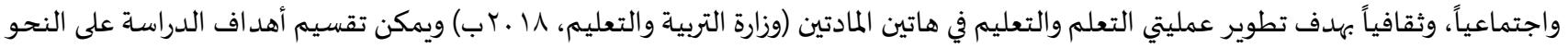
التالي (وزارة التربية والتعليم، د.تهافيا ولهدف):

قياس مستوى تحصيل الطلبة في مادتي الرياضيات والعلوم وفق المعايير الدولية. توفير البيانات التي قد تساعد الدول في إجراء المقارنات بين دولة وأخرى، للتعرف على أسباب الاختلاف. تطوير طرق تدريس مادتي العلوم والرياضيات.

تحديد المهارات العلمية التي يمتلكها الطلبة المشاركين في الدراسة ومدى امتلاكهم لها. الإسهام في توفير بيانات لصانعي القرار في المؤسسات التربوية؛ لتطوير نظم التعليم في الدولة.

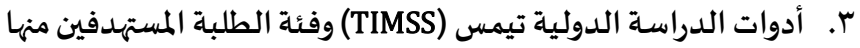

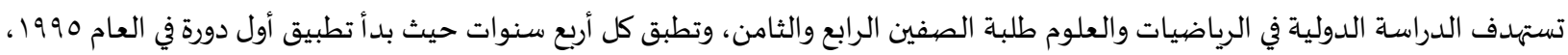

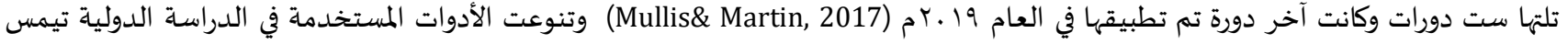
(TIMSS)

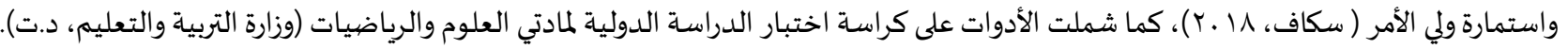

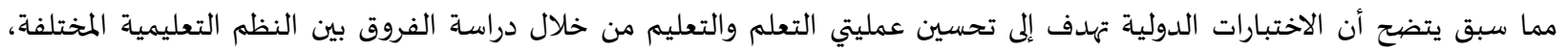
وتفسيرها، وتنفذ هذه الاختبارات باستخدام أداتين هما: الاستبانات لكل من الطالب، وولي أمره، ومعلمهاه، ومدير مدرستهاء، كما تستخدم الاختبارات للطلبة المستهدفين.

المحور الثاني: المشكلات التي تواجه إدارات المدارس في الاختبارات الدولية تواجه إدارات المدارس العديد من المشكلات التي تعيق عملها في رفع أداء الطلبة التحصيلي، وتختلف هذه المشكلات باختلاف الظروف الداخلية،

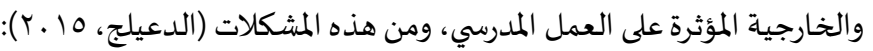
ا. قلة تجاوب أولياء الأمور مع المدرسة: وقد يعود ذلك إلى عدم إدراك أولياء الأمور بأهمية التكامل بين البيت والمدرسة، كذلك قد يعود إلى عدم قدرة مديري المدارس على خلق جو من الثقة المتبادلة بين المدرسة والأسرة.

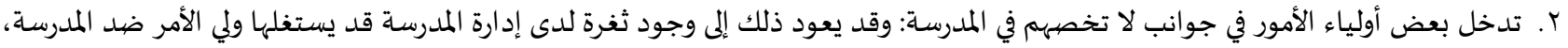

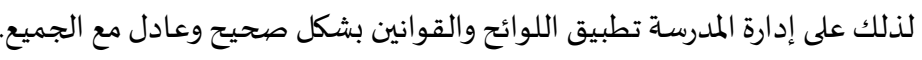
r. غياب المعلمين أو تأخرهم عن المدرسة: وهذا يسبب فقدًا في زمن التعلم الخاص بالطالب، فعلى فعلى إدارة المدرسة تتبع هذه الحالات واتخاذ الإجراءات القانونياة بحقهم. ع. وجود معلمين غير مؤهلين: وهنا لا بد من حصر هؤلاء المعلمين وتحديد جوانب القصور لديهم، ورفح تقرير عنهم ليتم تدريههم وتأهيلهم.

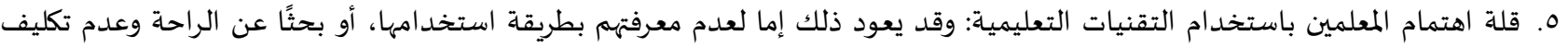
أنفسهم مشقة البحث عن هذه الوسائل.

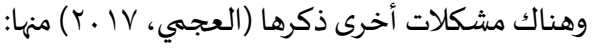

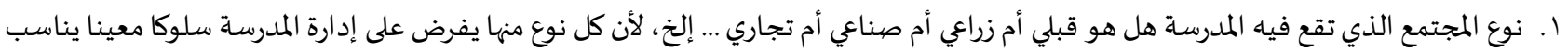
تحقيق رغبات أهله في تربية أبنائه.

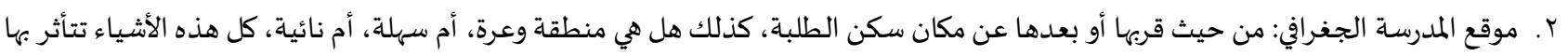

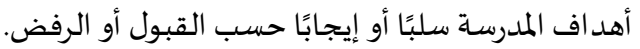

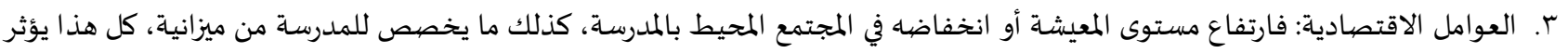
على جهود، ونشاطات المدرسة. مما سبق يتضح أن هناك العديد من التحديات التي تواجاء مديري المدارس لرفع المستوى التحصيلي للطلبة منها ما يتعلق ب: أولياء الامور،

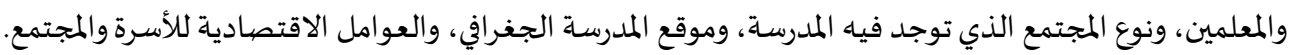


المحور الثالث: جهود سلطنة عمان في تطبيق الاختبارات الدولية

جاءت مشاركة السلطنة في الاختبارات الدولية تماشيا مع سعي وزارة التربية والتعليم لتطوير التعليم في سلطنة عمان، وسعيًا من الوزارة للحصول على تقويم للنظام التعليمي بالسلطنة من جهات خارجية محايدة، وللتعرف على موقع الأداء التعليمي بالسلطنة على المستوى العالمي وحسب المعايير الدولية.

ففي عام 0 . . ا م تم التواصل مع الجمعية الدولية لتقويم التحصيل التربوي (IEA)، لإبداء رغبة السلطنة في المشاركة في دورة V. . . من الدراسة الدولية في الرياضيات والعلوم للصف الثامن فقط، وقد سعت الوزارة لاتخاذ الإجراءات اللازمة للمشاركة في هذه الدراسة؛؛ حيث تم تشكيل الفريق الوطني الذي قام بتنفيذ الدراسـة على عينة من مدارس السلطنة، التي تم اختيارها من قبل الجمعية الدولية لتقويم التحصيل التربوي، وتضمّمن الفريق

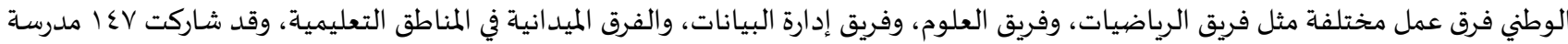

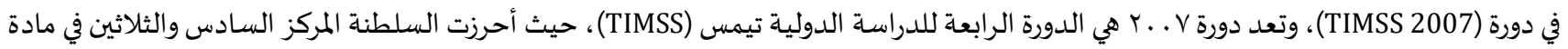
العلوم، والمركز الواحد والأربعين في مادة الرياضيات من بين تسعة وأربعين دولة شاركت في امتحان الدراسة الدولية للرياضيات والعلوم للصف الثامن (وزارة التربية والتعليم، د.ت). جاءت المشاركة الثانية للسلطنة في الدارسة الدولية تيمس (TIMSS) في دورتها الخامسة في عام Iا ـ. ، وتضيمنت الصفين الرابع والثامن، وكشفت نتائج تيمس (TIMSS) في الدول العربية بشكل عام أن طلبة الصف الرابع لديهم ضعف عام في القدرات الرياضية، والقدرات العلمية، وظهر ذلك من خلال متوسطاتهم التي لم تبلغ المستوى الدولي في أي دولة من الدول العربية المشاركة (الهادي، 10 ــب).

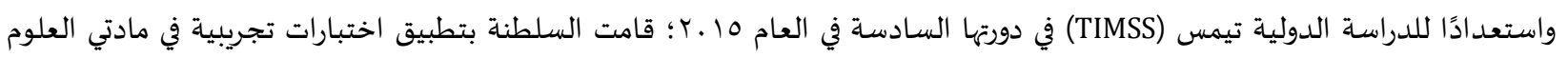
والرياضيات للصفين الرابع والثامن، لعينة من المدارس الحكومية بالسلطنة تمثلت في ست محافظات هي: مسقط، وجنوب الباطنة، وشمال الباطنة،

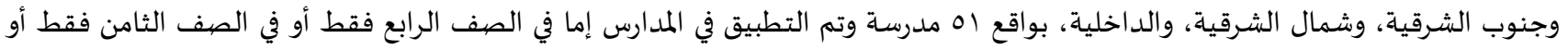
الصفين معًا (الرابع والثامن)، وأطلقت السلطنة حملة إعلامية استعدادا للدراسة الدولية (TIMSS 2015) تحت شعار: "لنجعل عمان تفخر بنا"

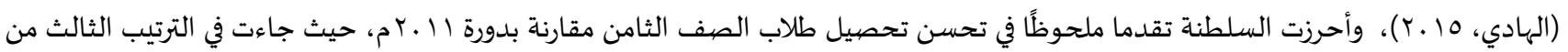

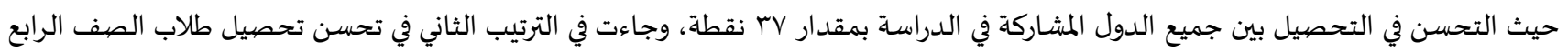

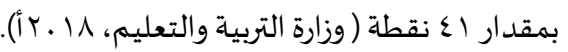

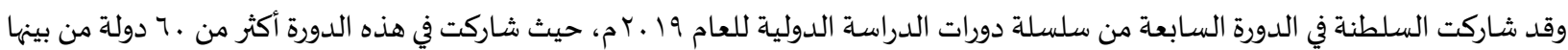

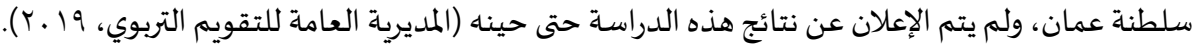

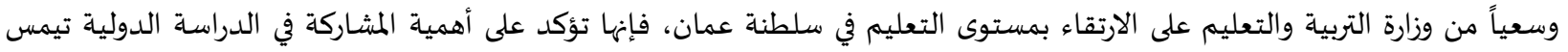
(TIMSS)

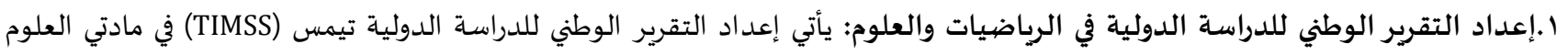
والرياضيات تزامنا مع ظهور نتائج الدراسة الدولية من الجمعية الدولية لتقييم التحصيل التربوي (IEA)، ويتم إعداد التقرير من قبل دائرة التقويم

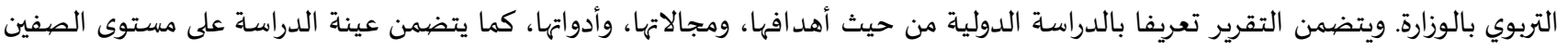

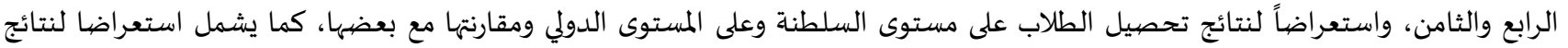

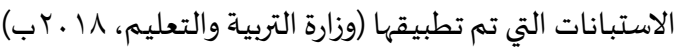
r. إعداد دليل مفردات الدراسة الدولية في الرياضيات والعلوم: سعت الوزارة متمثلة في المديرية العامة للتقويم التربوي لإعداد دليل تيمس (TIMSS)

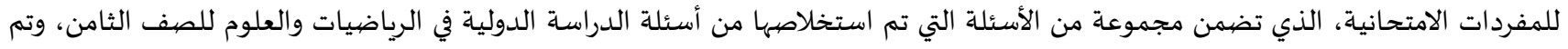

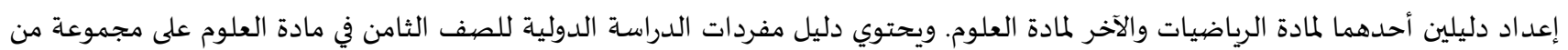
الأسئلة، تتضمن مجالات: الأحياء، والفيزياء، والكيمياء، وعلوم الأرض، وتمت صياغة الأسئلة على هيئة أسئلة اختيار من متعددد، وأسئلة مقالياه،

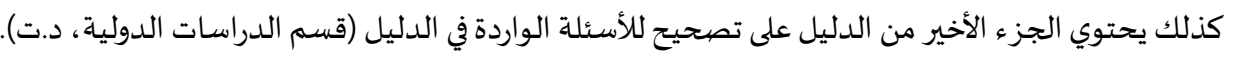
r. تطبيق مناهج سلاسل العلوم والرياضيات: جاء تطبيق الوزارة لمناهج سلاسل العلوم والرياضيات؛ سعيًا منها لتطوير التعليم بما يتواءم مع

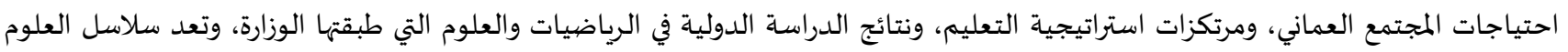
والرياضيات جزءًا من منظومة التعليم التي تعمل عليها الوزارة وتهدف إلى تحسين تدريس مادتي العلوم والرياضيات، وتحسين نتائج الطلبة في الدراسة

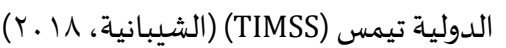


يتضح مما سبق مدى اهتمام سلطنة عمان بالاختبارات الدولية ونتائجها، ومن ثم توظيف هذه النتائج بما يساعد في رفع مستوى التعليم في السلطنة. وقد انعكس هذا الاهتمام في دراسـة النتائج وإعداد التقارير وتدريب الطلبة والمعلمين على نمارئ نماذج أسئلة الاختبارات الدولية، وصهولا إلى تطبيق مناهج سلاسل العلوم والرياضيات تماشيًا مع نتائج اختبارات الدراسـة الدولية.

الدراسات السابقة:

تناولت العديد من الدراسات موضوع الدراسة الدولية تيمس (TIMSS) والعناصر المؤثرة فيها: فقد أجرى الهطالي وآخرون (19 ـ (Y) دراسـة هدفت إلى التعرف على أسباب تدني مستوى طلبة الصف الثامن في اختبار (TIMSS 2015) لمواد العلوم والرياضيات بمحافظة جنوب الباطنة، واعتمدت المنهج الوصفي من خلال تطوير استبانة، تم توزيعها على (.ع) معلمًا و (یع) مشرفًا،

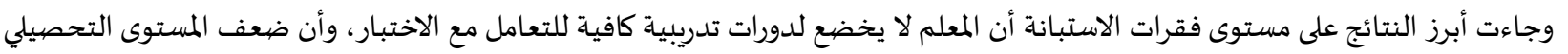

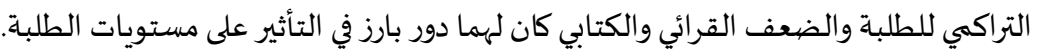
كما أجرى شحادة (17 ـ إ) دراسة هدفت إلى معرفة أسباب تدني مستوى أداء طلاب المملكة العربية السعودية في الرياضيات والعلوم في اختبار

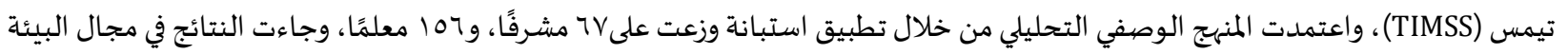
المدرسية كالتالي: لدى بعض الطلاب شعور بعدم الانتماء للمدرسة، قلما تهتم المدرسة بتعزيز ثقافة المواطنة والانتماء لدى الطلاب، لا تتسم بيئة

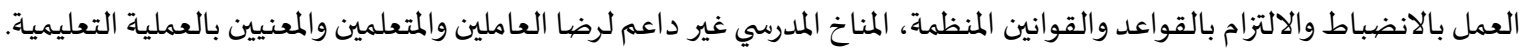
في حين هدفت دراسة المقيمية (7 ( ا ب إلى الكشف عن مدى تأثير المناخ المدرسي على نتائج الطلبة في مادة العلوم في (TIMSS 2011)، واعتمدت

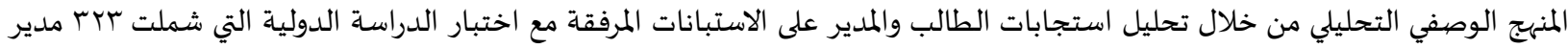

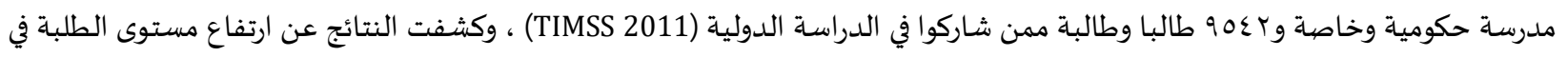

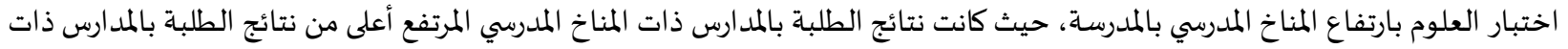

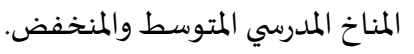
وقام مصلح (10 • r) بدراسة هدفت إلى التعرف على درجة تقديرات المشرفين التربويين لأسباب ضعف التحصيل الدراسي لدى طلبة المرحلة

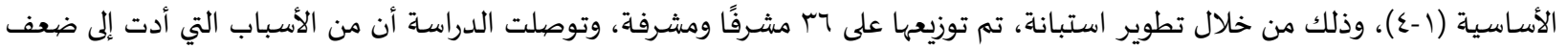

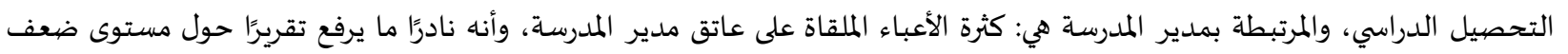
التحصيل في المدرسة، وأوصت الدراسة بضرورة تخفيف الأعباء على مدير المدرسة؛؛ ليتمكن من القيام بواجباته على الوجه الأكمل. وأجرى جانجيتوفك ومالينيك (Janjetovic \& Malinic, 2004) دراسة هدفت إلى التعرف على المتغيرات الأسرية المتعلقة بمادتي العلوم

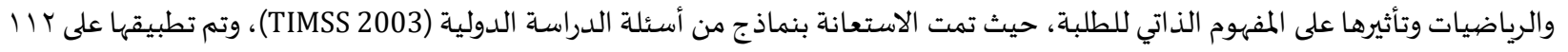

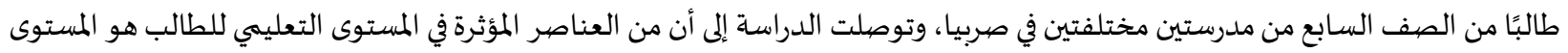

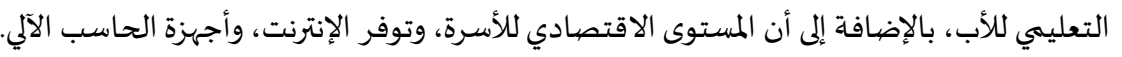
في ضوء ما تقدم، يمكن ملاحظة اختلاف نتائج الدراسات السابقة باختلاف الهدف منها، مع تأكيدها، بشكل عام، على وجود تأثير لمدير المدرسة

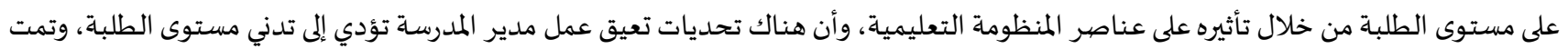
الاستفادة من الدراسات السابقة في عدة نقاط، أهمها:

تأكيد مشكلة الدراسـة وأهميتها. تحديد محاور أداة الدراسـة. تحديد منهج الدراسـة والأداة المناسبة لجمع البيانات. تحديد محاور الإطار النظري للدراسـة. مناقشـة نتائج الدراسـة. منهجية الدراسة وإجراءاتها:

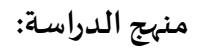
استخدمت الدراسة المنهج الكيفي باستخدام أسلوب البحث النوعي (Qualitative Research) لأنها يعد الأسلوب الأنسب للتعرف عن قرب على المالى التحديات التي تواجه مديري المدارس في سعيهم لتحسين مستوى الطلبة في الدراسة الدولية تيمس (TIMSS)، والآليات المقترحة لمواجهة هذه 
التحديات، حيث عرفه بوجدام وبيكلن (Bogdam \& Biklen, 1997) بأنه منهجية بحث تركز على وصف الظواهر وصفًا دقيقًا، كذلك تركز على الفهم الأعمق لها، ويختلف عن البحث الكمي الذي يعتمد على المعطيات العددية، لتحقيق هدف الدراسـة تم استخدام تصميم دراسة التجربة الشخصياة

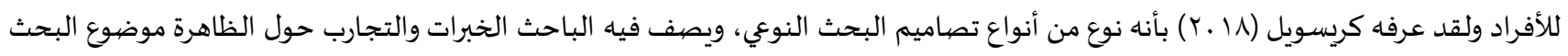

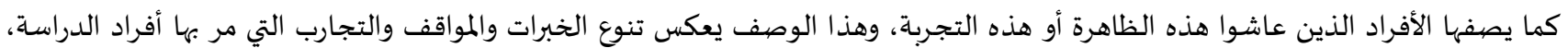
ويتطلب هذا التصيميم في الغالب إجراء مقابلات مع أولئك الأفراد.

\section{مجتمع الدراسة وعينتها:}

تكوّن مجتمع الدراسة من جميع مديري المدارس الحكومية التي طبقت فيها الدراسة الدولية تيمس (TIMSS) للصف الرابع في عام 0 اـب، وعام

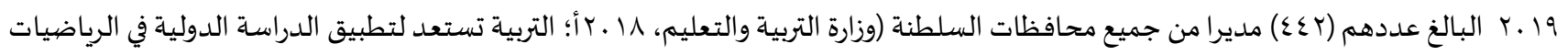
والعلوم، 19 . (Y).

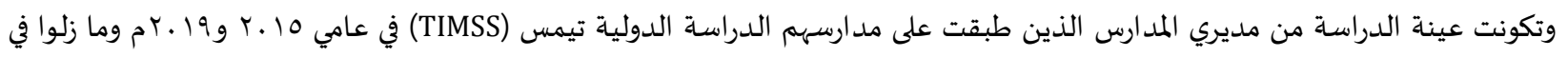

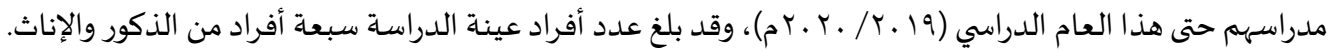
أداة الدراسـة:

للإجابة عن أسئلة الدراسةة تم استخدام أداة المقابلة، التي تعد من الأدوات الرئيسة في البحث النوعي. وتعرف المقابلة بأنها نوع خاص من المحادثة أو الحوار مع شخص له علاقة بموضوع البحث، ويستخدمه الباحث ليكتشف خبرة المستجيب وتفسيراته (Hatch, 2002)،

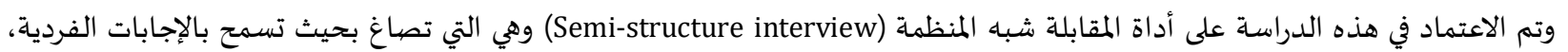
وتكون الأسئلة فيها مفتوحة ولكن محتواها محدد، وتتميز بأها تسمح بوجود علاقة تفاعلية بين الباحث والمستجيب (أبوعلام، ع . . ب)، وتم بناء الأداة وفق الخطوات التالية: ا. تحديد الهدف من المقابلة الذي تمثل في الكشف عن التحديات التي واجهت إدارات المدارس في الدراسة الدولية تيمس (TIMSS)، وآلية التغلب r. صياغة أسئلة المقابلة فقد تمت صياغة أسئلة المقابلة بناء على الهدف من الدراسـة، وتم اختيار هذه الأسئلة في ضوء خبرات الباحثين، وكذلك بناء على الأدبيات التي تم الاطلاع عليها، وبالاستفادة من بعض الدراسـات السابقة، حيث اشتملت الأسئلة على سؤال رئيسي مع خمسـة أسئلة فرعية حول التحديات التي تواجه مديري المدارس في تحسين أداء الطلبة في الاختبارات الدولية، كما تم طرح سؤال رئيسي آخر وخمسـة أسئلة فرعياة بهدف التعرف على آليات التغلب على التحديات

(Validity) الصيدق

يتطلب الوصول إلى نتائج سليمة وذات مصدداقية عالية في البحث العلمي أن يتأكد الباحث من صدل الأداة التي يستخدمها في جمع المعلومات،

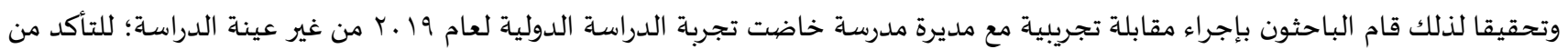

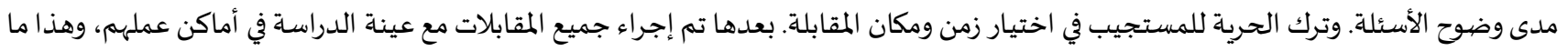

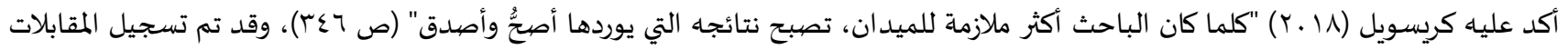
باستخدام جهاز تسجيل صوتي، ثم تم تفريغها وتحويلها إلى مقابلات مكتوبة وجاهزة للتحليل.

(Reliability) الثبات

لتحقيق الثبات تم فحص البيانات الخام التي تم الحصول عليها للتأكد من عدم وجود أخطاء في تدوين البيانات، وذلك من خلال إعادة الاستماع

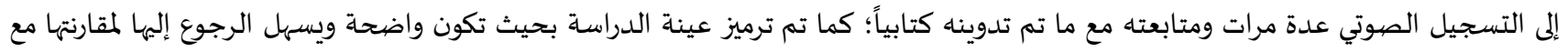

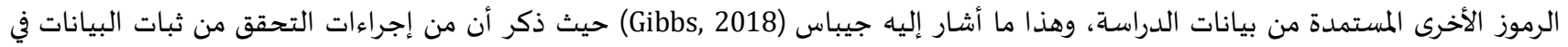

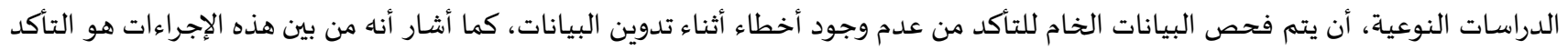
من عدم وجود خلط في ترميز البيانات، أو عدم وجود تغيير في معنى الرموز المستخدمة للنيات البيانات.

إجراءات تطبيق الدراسة الميدانية:

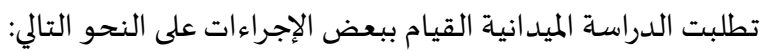
ا. التواصل مع دائرة التقويم التربوي بوزارة التربية والتعليم والحصول على البيانات المتعلقة بالدراسة الحالية من قسم الدراسـات الدولية.

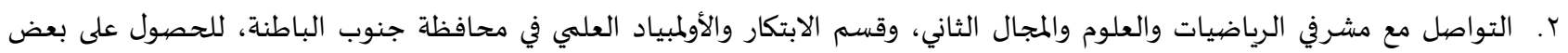
الدراسات السابقة ذات الصلة بالدراسة الحالية. 
r. إعد اد أسئلة المقابلة وتقسيمها إلى محاور من خلال الاطلاع على الدراسـات السابقة والأدب النظري، وعرضها على بعض الباحثين ذو الاختصاص لتحكيمها واعتمادها. ع. إجراء مقابلة تجريبية مع مدير مدرسة من خارج عينة الدراسة للتأكد من وضوح أسئلة الدراسة، وتحقيقها للهدف من الدراسة، ومعرفة الزمن المستغرق في الإجابة عن الأسئلة.

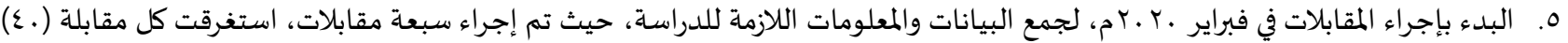
دقيقة. ومن ثم العمل على تحويل المقابلات الصيوتية إلى مقابلات مكتوبة.

\section{جمع البيانات وتحليلها:}

مرت عملية جمع وتحليل البيانات بعدة خطوات تمثلت في: ا. التواصل هاتفياً مع مديري المدارس التي خاضت تجربة (TIMSS 2015) و (TIMSS 2019) لإعطائهم فكرة عن الدراسـة، واختيار عينهاه منهم تطبق

$$
\text { عليهم الدراسـة. }
$$

r. إجراء المقابلات الفردية وجها لوجها (Face to face interviews) مع أفراد العينة في المدارس التي يعملون بها، وتسجيل المقابلات باستخدام كل

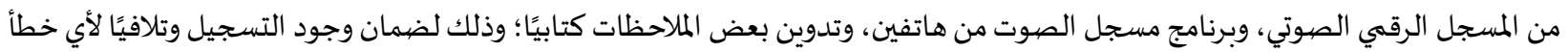
قد يحدث عن استخدام جهاز تسجيل واحد فقط. Y. تفريخ المقابلات كتابيًا، وذلك بعد الاستماع إليها وقد تم إعادة الاستماع عدة مرات للتأكد من أنهاء تم تفريخ جميع البيانات الموجودة بجهاز التسجيل، وإعطاء رموز للمستجيبين، مع ترميز البيانات وفق المعنى الذي تشير إلياه ليسهل تجميعها وفق محاور الدراسة. ع. تحليل النتائج من خلال تجميع الرموز وفق محاور الدراسة وإعطاء كل رمز اسمًا يناسب المحور الذي يندرج تحتها.

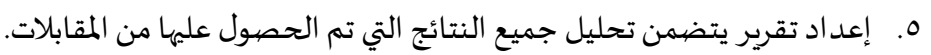

نتائج الدراسـة:

نتائج الإجابة عن السؤال الأول من أسئلة الدراسة ونصيه "ما التحديات التي واجهت مديري المدارس لتحسين مستوى الطلبة في الدراسة

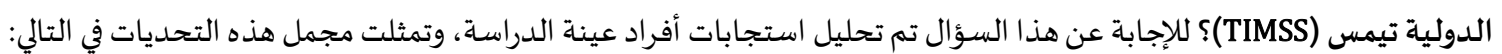
ا. و وجود فئة من الطلبة مستواهم التحصيلي دون المستوى المطلوب: لقد اتجهت جميع استجابات أفراد عينة الدراسة إلى وجود هذه التحدي

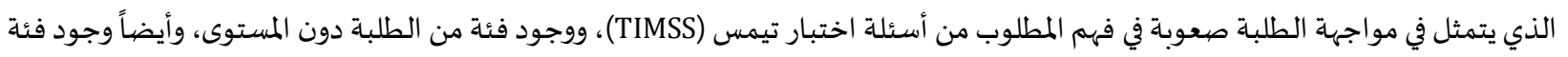
من الطلبة لديهم مشكلة الضعف القرائي، كذلك وجود فئة من طلبة الدمج الفكري مع طلبة الصف، أضف إلى ذلك وجود طلبة وافدين من غير الناطقين باللغة العربية في شعبة تيمس (TIMSS) قد قدموا إلى المدرسة في نفس العام الذي طبقت فيه الدراسة الدولية، بالإضافة إلى أن الحالات الاجتماعية لبعض الطلبة كحالات طلاق الوالدين أثر في مستوى الطالب، وفي هذا الصدد ذكر أحد أفراد عينة الدراسة: "فالمشكلة الكبيرة كانت في الطلبة غير الناطقين باللغة العربية".

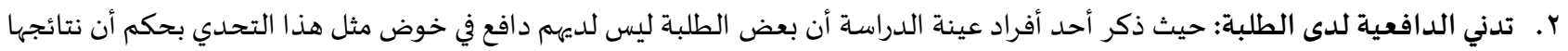

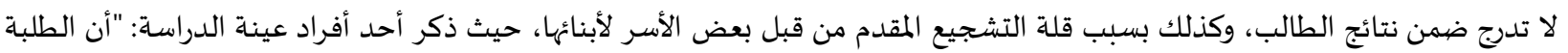
ليس لديهم د افع للدراسة الدولية، ماذا تخدمني هذه الدراسـة فـ ما الفائدة منها؟". r. قلة الدعم المقدم من قبل الوزارة: وقد أشـار جميع أفراد عينة الدراسـة لقلة المتابعة من قبل الأقسام الخاصة بالدراسة الدولية سواء من

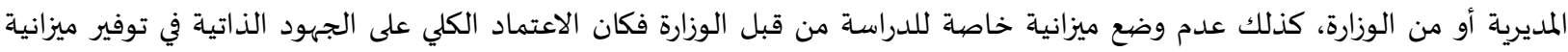

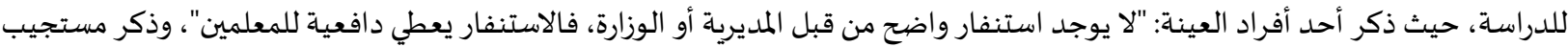

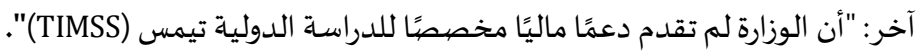

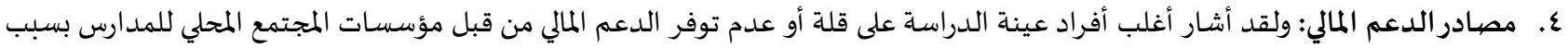

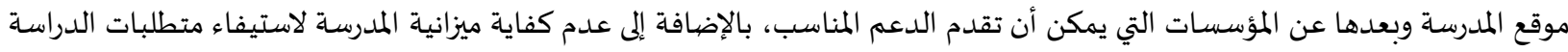
الدولية، حيث أشار أحد أفراد العينة: "ضغطت المداع المدرسة على ميزانيتها لمحاولة توفير الأدوات اللازمة للدراسة الدولية تيمس (TIMSS)". ه. ضعف مهارة بعض المعلمات في صياغة أسئلة تيمس (TIMSS): وقد أشار أحد أفراد عينة الدراسة إلى قلة معرفة المعلمات بطريقة صياغة ادواتة

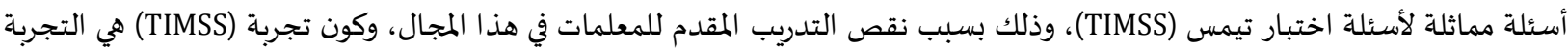

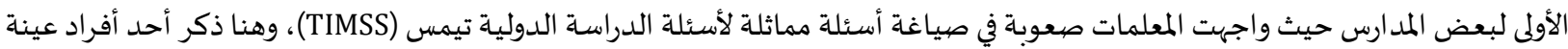

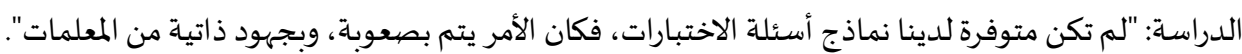


7 ا المستوى التعليمي لأولياء الأمور: وقد أشـار أحد أفراد عينة الدراسـة إلى وجود فئة من أولياء الأمور لم يصلوا لمراحل متقدمة من التعليم، فلم

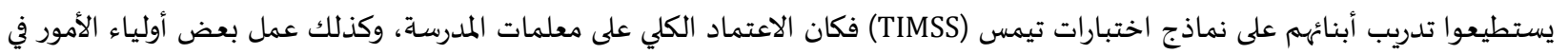

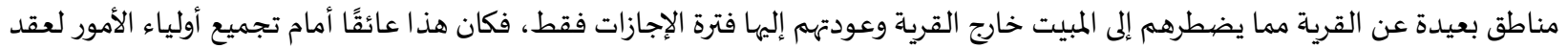

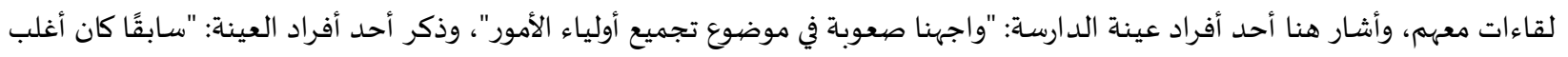

$$
\text { أولياء الأمور مستواهم التعليمي متدنٍٍ." }
$$

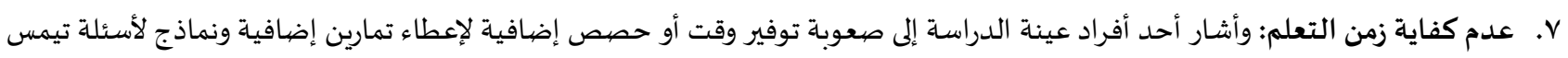

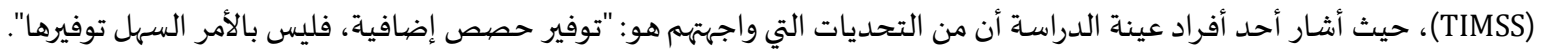

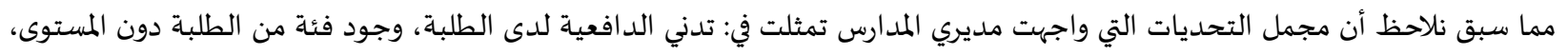

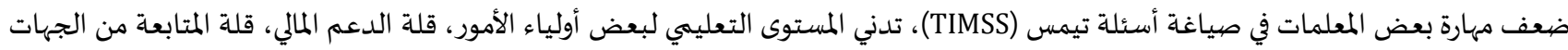

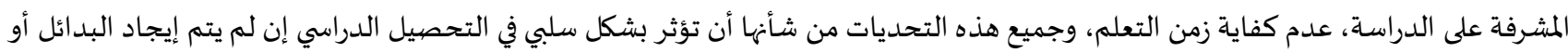

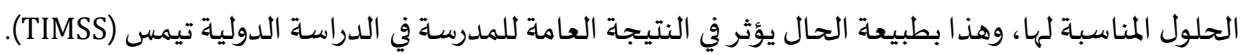
وترجع أسباب وجود هذه التحديات إلى أن بعض هذه المدارس تقع في مناطق نائية، وبعض المهدئه المدارس بها فئة كبيرة من الطلبة دون المستوى ولم

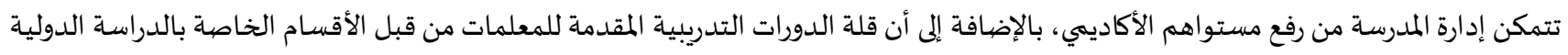

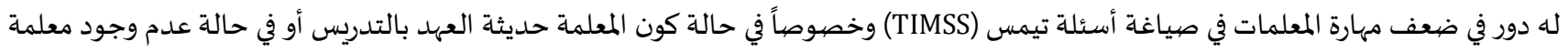

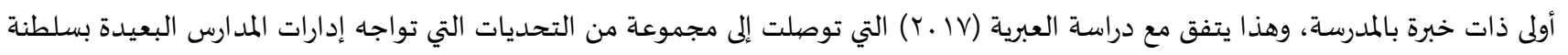

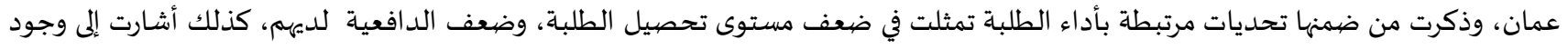

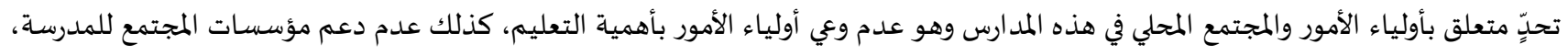

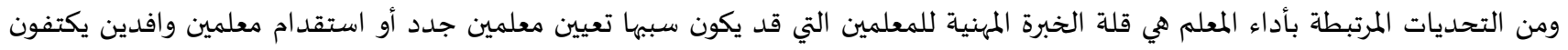
باستخدام الطرق التقليدية في التدريس.

الإجابة عن السؤال الثاني ونصه "ما الآليات المقترحة للتغلب على التحديات التي تواجه مديدي مديري المدارس لتحسين مستوى الطلبة في

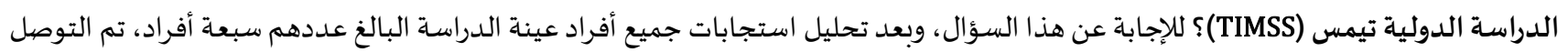

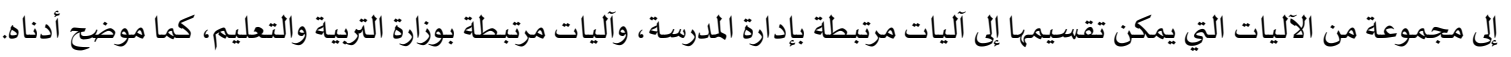

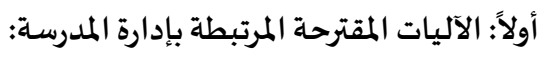

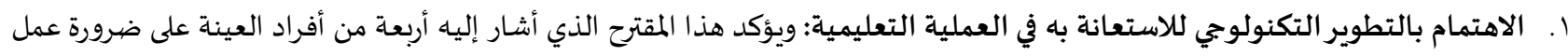

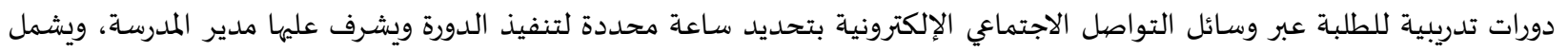

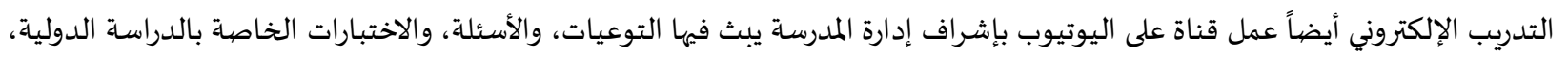
كذلك عمل منصة تدريبية مختصية بالدراسة الدولية تيمس (TIMSS)، ولتحقيق هذا المقترح يراعى توفير الأجهزة الإلكترونية التعليمية لطلبة الإسية

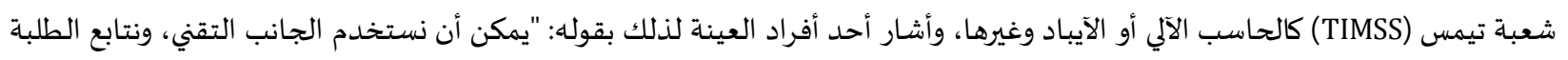
وهم في البيت، ونقدم لهم التغذية الراجعة". وأشـار آخر في هذا الصديداد: "عمل قناة على اليوتيوب لبث التوعيات، والمسابقات، والأسئلة،

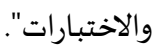

ب تفعيل ممارسات ولي الأمر في الدراسـة الدولية: وأكد على هذا المقترح أربعة من أفراد العينة ويقصد بهذا المقترح هو أن يكون ولي الأمر شريكًا

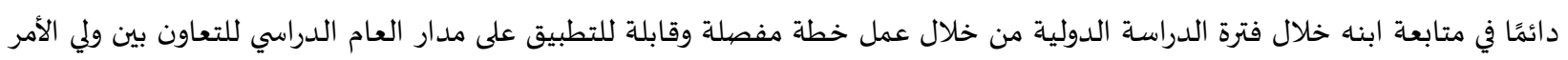

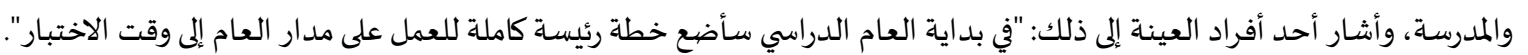

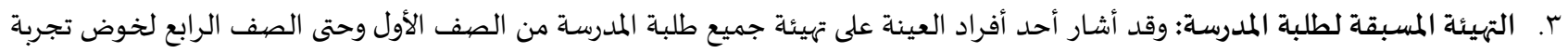

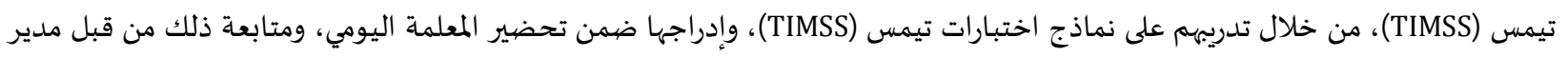
المدرسـة، وذكر أحد أفراد عينة الدراسة ذلك: "تهيئة الطلبة من الصفف الأول إلى أن يصلوا للصف إسف الرابع".

ثانياً: الآليات المقترحة المرتبطة بوزارة التربية والتعليم: ودردئ

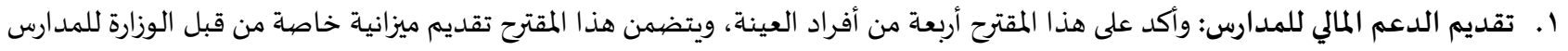

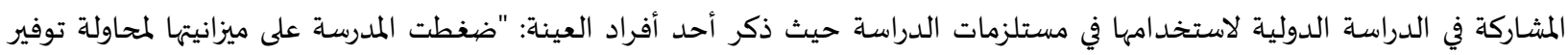
الأدوات اللازمة لتيمس (TIMSS)، بينما لو كانت هناك ميزانية خاصة من المؤكد أننا نستطيع زيادة عدد الكتيبات والتشجيع". 


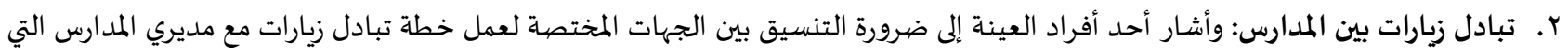

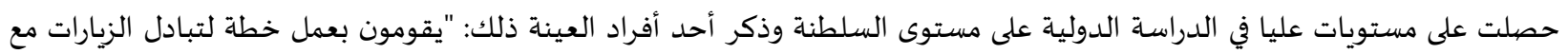
المدارس التي تميزت في تيمس (TIMSS)؛ لتبادل الخبرات".

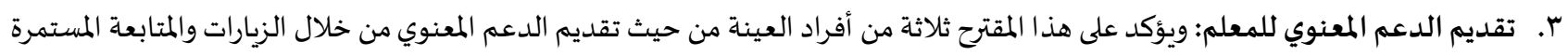

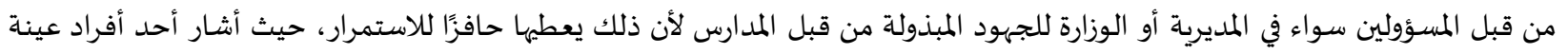

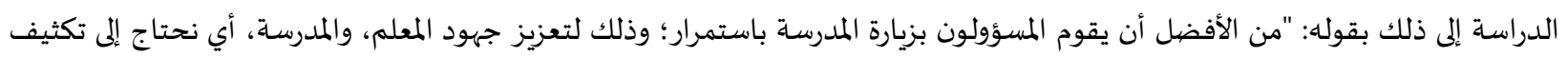

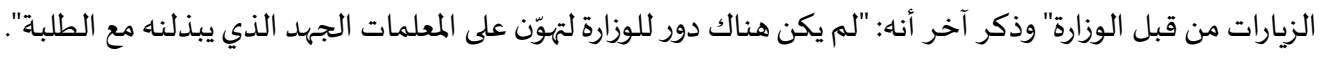

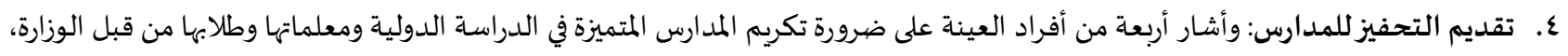

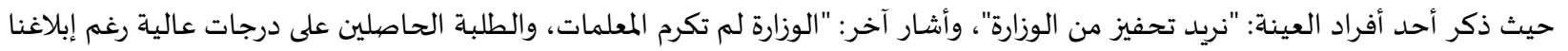
بأنها سيتم تكريم المدارس المتميزة".

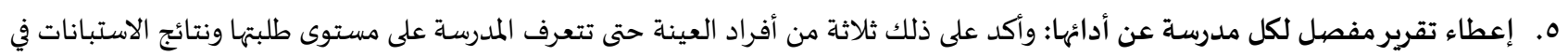

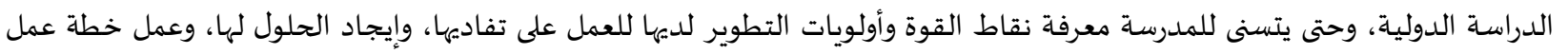

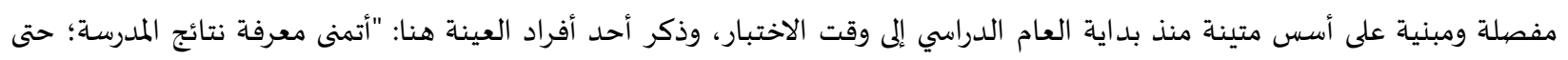

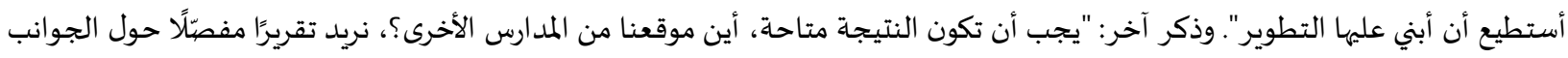

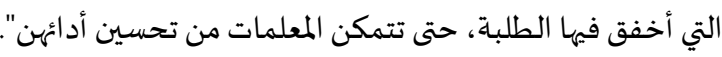

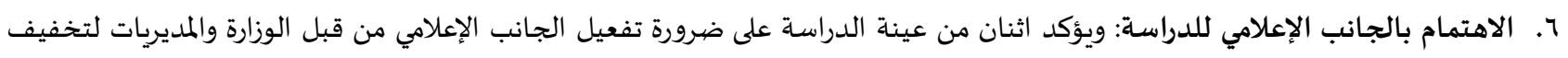

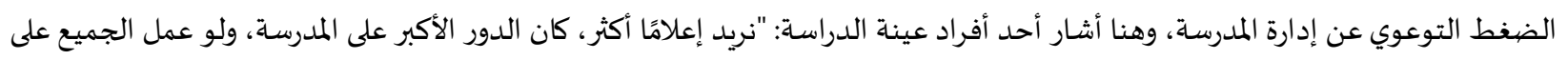
تفعيل الجانب الإعلامي سيكون هناك اهتمام أكثر ، وسيشعر أولياء الأمور بمسؤولية ألمات ألمبر".

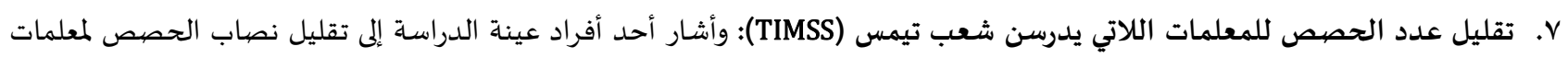

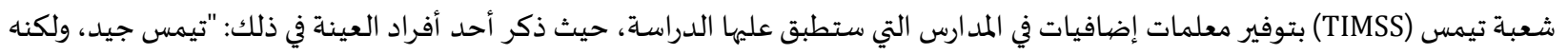

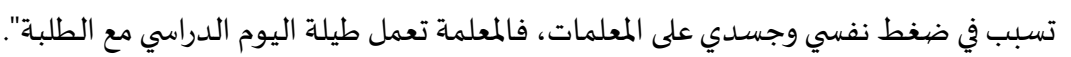

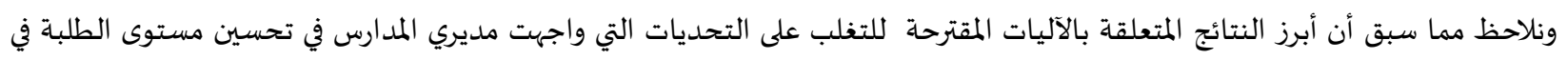

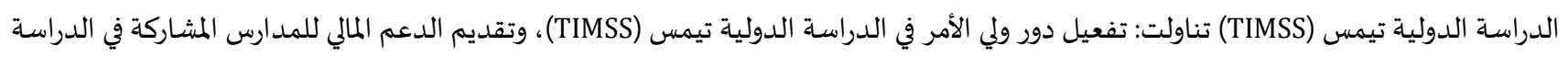

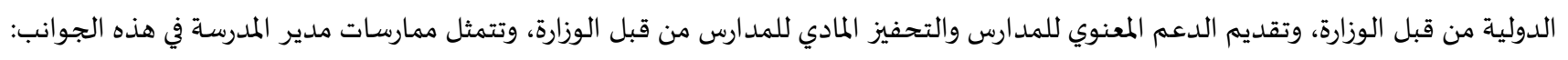

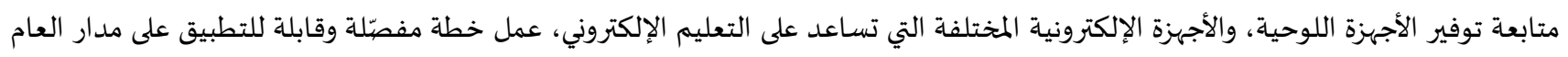

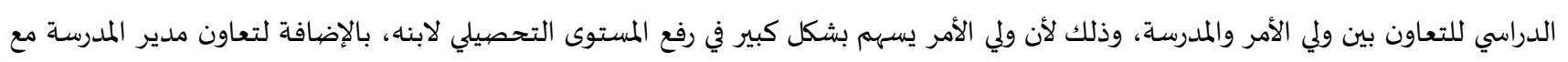

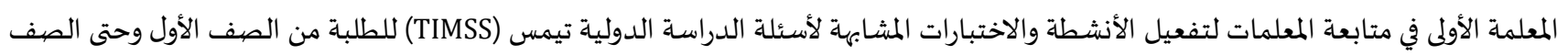

أما بالنسبة للمقترحات الخاصةة بالوزارة فتمثلت في: تخصيص الوزارة جزء من المالية للمدارس المشاركة في الدراسة الدولية تيمس (TIMSS)

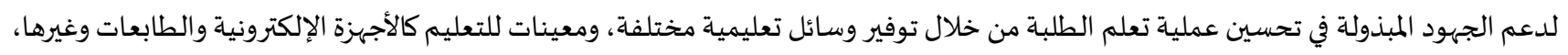

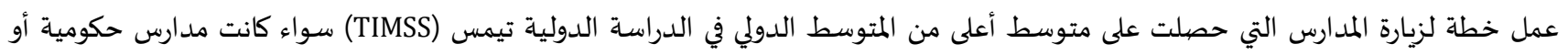

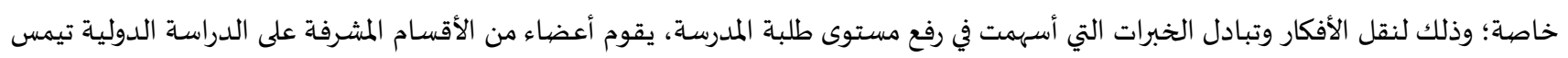
(TIMSS)

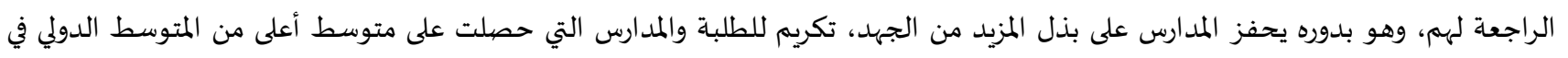

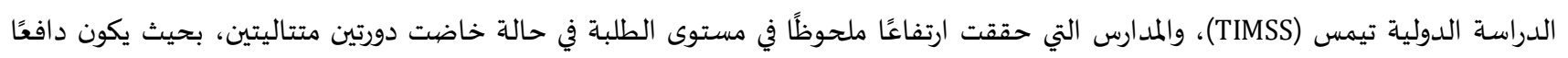

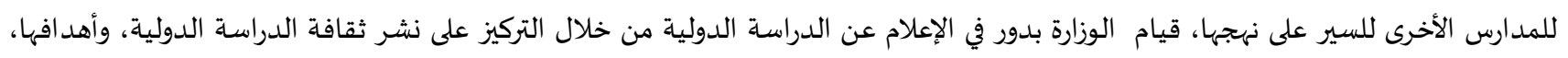

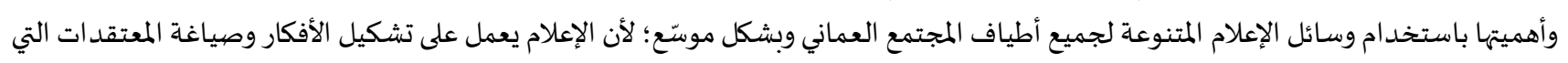

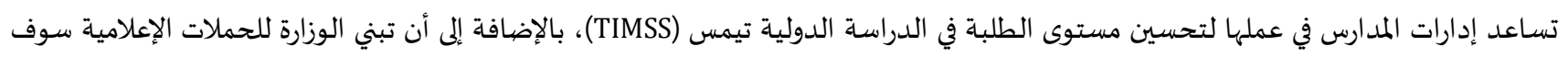

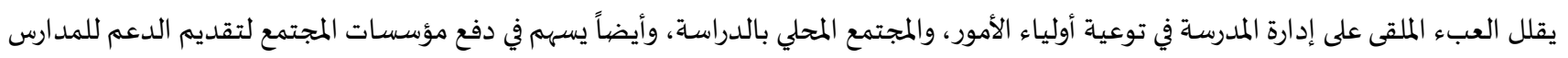
المشاركة في الدراسة الدولية. 
توصيات ومقتراحات الدراسـة:

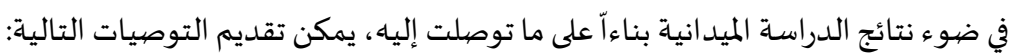
1. تهيئة المناخ المناسب لعمليتي التعلم والتعليم.

r. تدريب كوادر وطنية لضيمان استمرار وجود هذه الكوادر في الميدان.

r. التنسيق مع الدوائر الخاصة بالتقويم التربوي لاستمرار عملية التقويم من بداية العام الدراسي إلى نهايته.

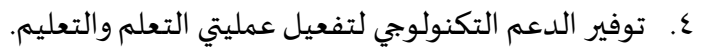

0 ه. عمل خطط متابعة مكثفة للمدارس المشاركة في الدراسة الدولية تيمس (TIMSS) من قبل الأقسام المسؤولة عن الدراسة الدولية سواء في

المديرية أو في الوزارة.

7 7. تقديم الوزارة للدعم المالي للمدارس التي يقع عليها الاختيار في تطبيق الدراسة الدولية تيمس (TIMSS).

V. ت تكثيف الحملات الإعلامية حول الدراسة الدولية تيمس (TIMSS) بالتنسيق بين وزارة التربية والتعليم ووزارة الإعلام.

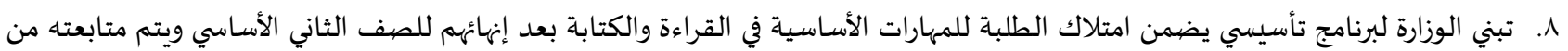

قبل المشرفين التربويين.

9 . إعد اد برنامج تبادل زيارات بين مديري المدارس؛ لزيارة المدارس التي حصيلت على معدل أعلى من المتوسط الدولي في اختبار تيمس (TIMSS).

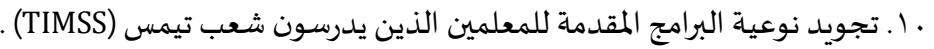

11 . العمل خطط مسبقة لتدريب المعلمين الذين لديهم الرغبة في تدريس شعب تيمس توعس (TIMSS).

أولًا: المراجع العربية:

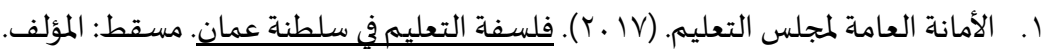

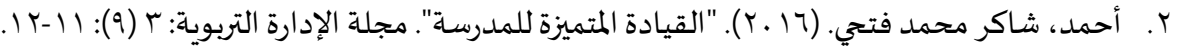

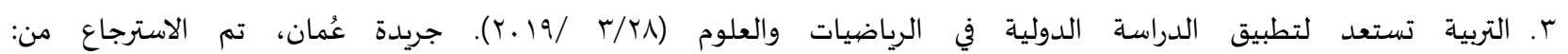
https://www.omandaily.om/?p=685638

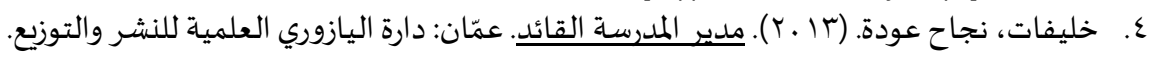

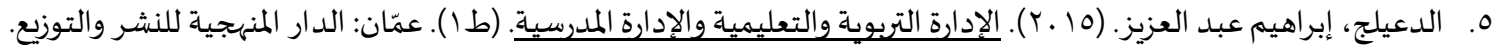

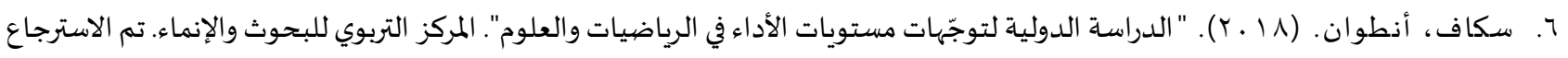

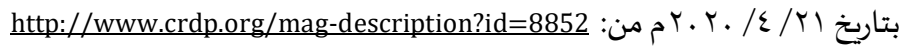
V. شحادة، فواز حسن إبراهيم والقراميطي، أبو الفتوح مختار. (17 . (Y). "مستوى تحصيل طلبة المملكة العربية السعودية في الرياضيات والعلوم

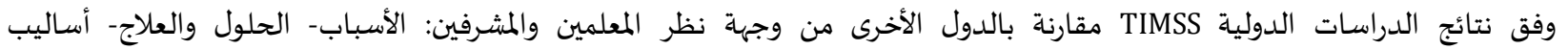

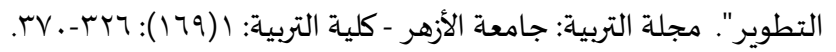

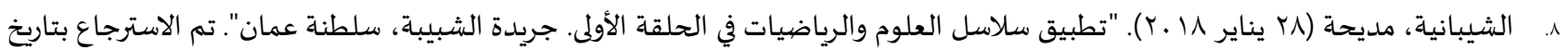

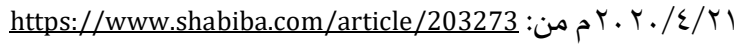

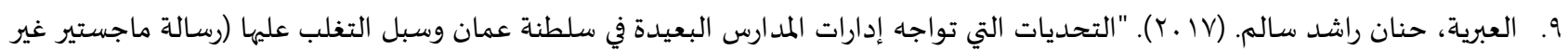
منشورة)". جامعة السلطان قابوس. سلطنة عمان.

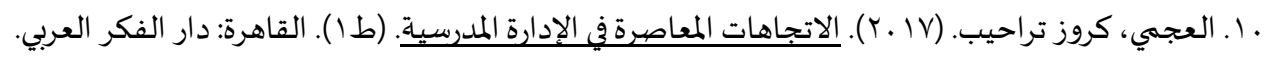

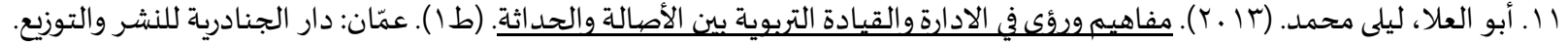

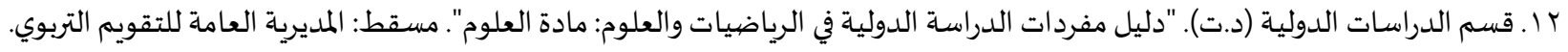

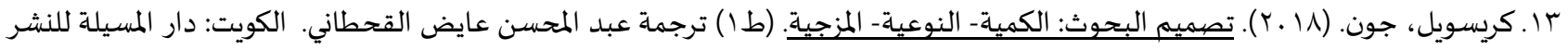
والتوزع. ع ا. اللجنة الرئيسية للسياسات التربوية وتطوير التعليم. (10 ـ.r). "دليل مهام الوظائف المدرسية والأنصبة المعتمدة لها". مسقط: وزارة التربية والتعليم. 0 ا ـ مجلس التعليم. (17 (Y). "التقرير السنوي للتعليم في سلطنة عمان". مسقط: المؤلف. 7 ا ـ المديرية العامة للتقويم التربوي. (9 19 ـ). TIMSS2019 دليل منسقي المدارس. مسقط: وزارة التربية والتعليم. 


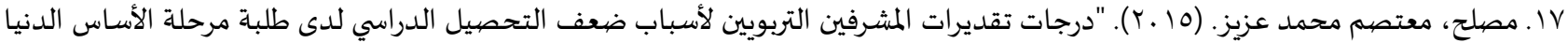

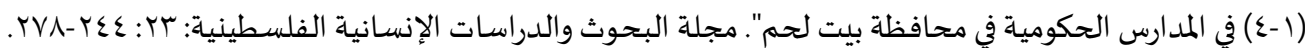

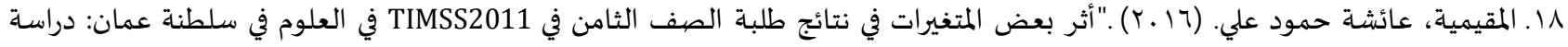

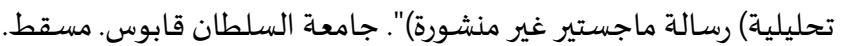

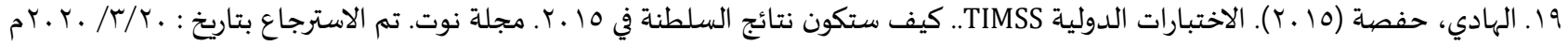
http://note-mag.com/archives/4563 : من

• . . الهطالي، محمد سليمان والحكماني، رحاب سعيد والبحري، خالصة حمد والرمجي، سالم راشد والشقصي، يعقوب زاهر. (19 ـ ب). "أسباب تدني طلبة الصف الثامن في اختبار TIMSS لمادتي العلوم والرياضيات بمحافظة جنوب الباطنة من وجهة نظر المشرفين والمعلمين". دائرة التقويم التربوي: محافظة جنوب الباطنة، سلطنة عمان.

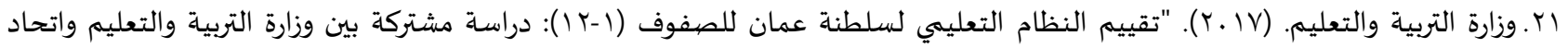

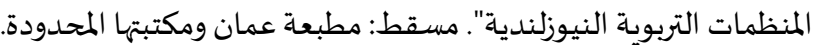

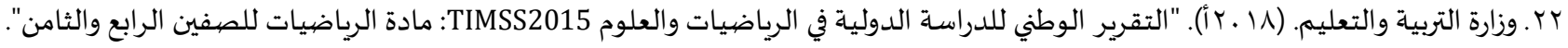
مسقط: مطبعة عمان ومكتبتها المحدودة.

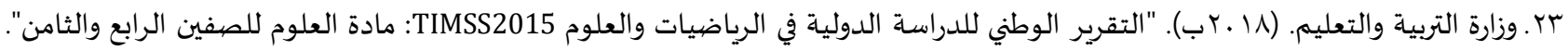
مسقط: مطبعة عمان ومكتبتها المحدودة. ع ع. وزارة التربية والتعليم. (د.ت). "الدراسة الدولية في الرياضيات والعلوم TIMSS 2007 ". مسقط: المؤلف. ثانيًا: المراجع الأجنبية:

[1] Bogdan, R., \& Biklen, S. K. (1997). "Qualitative research for education”. Boston, MA: Allyn \& Bacon.

[2] Gibbs, G. R. (2018). “Analyzing qualitative data (Vol. 6)”. Sage.

[3] Hatch, J. A. (2002). "Doing qualitative research in education settings". New York: Suny Press.

[4] International Association for the Evaluation of Educational Achievement (2020). IEA Researching education, improving learning. From: https://www.iea.nl/ar/intro

[5] Janjetovic, D., \& Malinic, D. (2004). "Family variables as predictors of mathematics and science self-concept of students". In 1st IEA International Research Conference. from: https://www.iea.nl/news-events/irc/3rd-iea-internationalresearchconference

[6] Mullis, I. V., \& Martin, M. O. (2017). "TIMSS 2019 Assessment Frameworks". The Netherlands: International Association for the Evaluation of Educational Achievement. 
المجلة الدولية للدراسـات التربوية والنفسية

International Journal of Educational \& Psychological Studies (EPS)

Journal Homepage: https://www.refaad.com/views/EPSR/Home.aspx

www.refaad.com

ISSN: 2520-4149 (Online) 2520-4130 (Print)

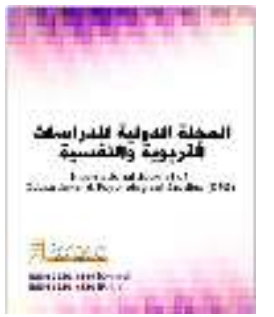

\title{
Challenges facing school principals in the Sultanate of Oman in improving students' performance in international tests (TIMSS) and mechanisms to overcome them
}

\section{${ }^{1}$ Mona Said Al-Tobi, ${ }^{2}$ Omer Hashim Ismail Hamad, ${ }^{3}$ Mohammed Abdul Hamied Lashin}

1 Ministry of Education, Sultanate of Oman

2,3 College of Education, Sultan Qaboos University, Sultanate of Oman

1 muna.altobi@moe.om, 2 omerhi@squ.edu.om, 3 lashin@squ.edu.om

\begin{abstract}
Received : 8/9/2020
Revised : 25/9/2020

Accepted : 3/10/2020

DOI : https://doi.org/10.31559/EPS2021.9.1.17

Abstract: This study aimed to identify the challenges facing school principals in the Sultanate of Oman in improving the level of students' performance in the Trends in International Mathematics and Science Study (TIMSS), and the mechanisms for overcoming them. To achieve this, the study followed the qualitative approach by using the qualitative research method. Data was collected using interviews, which were conducted with seven school principals whose schools have taken TIMSS in 2015 and 2019 and are still in their schools. The results of the study revealed a set of challenges that hinder school principals' efforts to improve students' performance in the TIMSS tests, including students whose achievement level is below the required level, low student motivation, lack of support provided by the Ministry of Education, and the weakness of teachers' skills in formulating TIMSS questions. The study suggested mechanisms that can limit these challenges, including those related to school management, such as enhancing use of technology in the educational process, involving guardian practices in international studies, and some of them are related to the Ministry of Education, such as providing financial support to schools, and exchanging visits between schools, providing moral support to schools, and motivating teachers. A number of recommendations were made, the most important of which are creating the appropriate climate for learning, training national cadres, and coordinating with the departments for educational evaluation to continue the evaluation process through the school year.
\end{abstract}

Keywords: School Principals; International Test (TIMSS); Sultanate of Oman.

\section{References:}

[1] Al'bryh, Hnan Rashd Salm. (2017). "Althdyat Alty Twajh Edarat Almdars Alb'ydh Fy Sltnh 'man Wsbl Altghlb 'lyha". (Rsalt Majstyr Ghyr Mnshwrh). Jam'eh Alsltan Qabws. Sltnh 'Eman.

[2] Al'jmy, Krwz Trahyb. (2017). Alatjahat Alm'asrh Fy Aledarh Almdrsyh. (T1). Alqahrh: Dar Alfkr Al'rby.

[3] Abw Al'la, Lyla Mhmd. (2013). "Mfahym Wr'a Fy Aladarh Walqyadh Altrbwyh Byn Alasalh Walhdathh". (T1). 'man: Dar Aljnadryh Llnshr Waltwzy'.

[4] Ahmd, Shakr Mhmd Fthy. (2016). "Alqyadh Almtmyzh Llmdrsh". Mjlt Aledarh Altrbwyh: 3 (9): 11-12.

[5] Alamanh Al'amh Lmjls Alt'lym. (2017). Flsft Alt'lym Fy Sltnh 'man. Msqt: Alm'lf.

[6] Ald'ylj, Ebrahym 'bd Al'zyz. (2015). "Aledarh Altrbwyh Walt'lymyh Waledarh Almdrsyh". (T1). 'man: Aldar Almnhjyh Llnshr Waltwzy'.

[7] Alhady, Hfsh. (2015). "Alakhtbarat Aldwlyh Timss.. Kyf Stkwn Nta'j Alsltnh Fy 2015". Mjlt Nwt: Tm Alastrja' Btarykh : 20/3/2020m Mn : http://note-mag.com/archives/4563

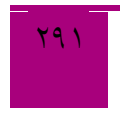


[8] Alhtaly, Mhmd Slyman Walhkmany, Rhab S'yd Walbhry, Khalsh Hmd Walrmhy, Salm Rashd Walshqsy, Y'qwb Zahr. (2019). "Asbab Tdny Tlbt Alsf Althamn Fy Akhtbar Timss Lmadty Al'lwm Walryadyat Bmhafzt Jnwb Albatnh Mn Wjht Nzr Almshrfyn Walm'lmyn". Da'rt Altqwym Altrbwy: Mhafzt Jnwb Albatnh. Sltnh 'man.

[9] Khlyfat, Njah 'wdh. (2013). Mdyr Almdrsh Alqa'd. 'man: Darh Alyazwry Al'Imyh Llnshr Waltwzy'.

[10] Kryswyl, Jwn. (2018). Tsmym Albhwth: Alkmyh- Alnw'yh- Almzjyh. (T1) Trjmt 'bd Almhsn 'ayd Alqhtany. Alkwyt: Dar Almsylh Llnshr Waltwzy'.

[11] Altrbyh Tst'd Lttbyq Aldrash Aldwlyh Fy Alryadyat Wal'lwm (28/3 /2019). Jrydt 'uman, Tm Alastrja' Mn: https://www.omandaily.om/?p=685638.

[12] Alljnh Alr'ysyh Llsyasat Altrbwyh Wttwyr Alt'lym. (2015). "Dlyl Mham Alwza'f Almdrsyh Walansbh Alm'tmdh Lha". Msqt: Wzart Altrbyh Walt'elym.

[13] Almdyryh Al'amh Lltqwym Altrbwy. (2019). Timss2019 Dlyl Mnsqy Almdars. Msqt: Wzarh Altrbyh Walt'lym.

[14] Mjls Alt'lym. (2016). Altqryr Alsnwy Llt'elym Fy Sltnh 'man. Msqt: Alm'lf.

[15] Almqymyh, 'a'shh Hmwd 'ly. (2016. ("Athr B'd Almtghyrat Fy Nta'j Tlbt Alsf Althamn Fy Timss2011 Fy Al'lwm Fy Sltnt 'man: Drash Thlylyh)". (Rsalt Majstyr Ghyr Mnshwrh). Jam't Alsltan Qabws. Msqt.

[16] Mslh, M'tsm Mhmd 'zyz. (2015). "Drjat Tqdyrat Almshrfyn Altrbwyyn Lasbab D'f Althsyl Aldrasy Lda Tlbh Mrhlt Alasas Aldnya (1-4) Fy Almdars Alhkwmyh Fy Mhafzt Byt Lhm". Mjlt Albhwth Waldrasat Alensanyh Alflstynyh: 23: 244-278.

[17] Qsm Aldrasat Aldwlyh (D.T). Dlyl Mfrdat Aldrash Aldwlyh Fy Alryadyat Wal'lwm: Madh Al'lwm. Msqt: Almdyryh Al'amh Lltqwym Altrbwy.

[18] Shhadh, Fwaz Hsn Ebrahym Walqramyty, Abw Alftwh Mkhtar. (2016). "Mstwa Thsyl Tlbh Almmlkh Al'rbyh Als'wdyh Fy Alryadyat Wal'lwm Wfq Nta'j Aldrasat Aldwlyh Timss Mqarnh Baldwl Alakhra Mn Wjht Nzr Alm'lmyn Walmshrfyn: Alasbab - Alhlwl Wal'laj - Asalyb Alttwyr". Mjlt Altrbyh: Jam't Alazhr - Klyt Altrbyh. 1(169): 326-370.

[19] Alshybanyh, Mdyhh. (2018). "Ttbyq Slasl Al'lwm Walryadyat Fy Alhlqh Alawla". Jrydt Alshbybh, Sltnh 'man. Tm Alastrja' Btarykh 21/4/2020m Mn: https://www.shabiba.com/article/203273.

[20] Skaf, Antwan. (2018). "Aldrash Aldwlyh Ltwjhat Mstwyat Alada' Fy Alryadyat Wal'lwm". Almrkz Altrbwy Llbhwth Walenma'. Tm Alastrja' Btarykh 21/ 4/ 2020m Mn: http://www.crdp.org/mag-description?id=8852.

[21] Wzart Altrbyh Walt'lym. (2017). "Tqyym Alnzam Alt'lymy Lsltnh 'man Llsfwf (1-12): Drash Mshtrkh Byn Wzart Altrbyh Walt'lym Wathad Almnzmat Altrbwyh Alnywzlndyh". Msqt: Mtb't 'man Wmktbtha Almhdwdh.

[22] Wzart Altrbyh Walt'lym. (2018a). "Altqryr Alwtny Lldrash Aldwlyh Fy Alryadyat Wal'lwm Timss2015" Madt Alryadyat Llsfyn Alrab' Walthamn". Msqt: Mtb't 'man Wmktbtha Almhdwdh.

[23] Wzart Altrbyh Walt'lym (2018b). "Altqryr Alwtny Lldrash Aldwlyh Fy Alryadyat Wal'lwm Timss2015" Madt Al'lwm Llsfyn Alrab' Walthamn". Msqt: Mtb't 'man Wmktbtha Almhdwdh.

[24] Wzart Altrbyh Walt'lym. (D.T). Aldrash Aldwlyh Fy Alryadyat Wal'lwm “Timss2007. Msqt: Alm'lf 